\title{
Language Teaching and Task Based Approach
}

\author{
Sayed Mahdi Rozati \\ Amin Higher Education Institution, Fouladshahr, Iran
}

\begin{abstract}
During recent years, some notions about tasks have been considered as the major part of analysis in different teaching approaches and teachers are being more interested in the use of task-based approach both in foreign and in second language teaching. The word 'task' refers to some special activities that are carried out in the classroom. These activities are performed by putting an emphasis on meaning. In this approach Grammatical Competence and communicative competence are extremely emphasised, that is being able to adjust with grammatical norms and being able to convey ideas. Consequently, grammatical competence in this approach is made by 'internal self-regulating processes' and it helps to convey the meaning in 'appropriate conditions'. The main goal of this article is to introduce and discuss some major principles of task-based language teaching and indicates how teachers can apply them in their curriculum.
\end{abstract}

Index Terms - task, grammatical competence, communicative competence, task-based language teaching

\section{INTRODUCTION}

Task- based language teaching is derived from Dewey's attitude about the crucial role of experience for an effective learning. It considers the functional role of language in real tasks as the major goal for students to communicate at the class for an ideal learning. Unlike traditional form-based approaches, task-based involves the specification of a sequence of interactive tasks to be performed in the target language rather than a sequence of language items. Language teaching has been affected by many changes for the last few decades. Many methods have been introduced. Teachers experienced Audio lingual Method, Total Physical Response (TPR), Natural Approach, and many other methods. It is generally believed that there is no single method that can meet the students' needs.

The major differences between task based and traditional approaches are shown in the following table:

TABLE 1:

DIFFERENCES BETWEEN TASK BASED AND OTHER APPROACHES

\begin{tabular}{|l|l|}
\hline Task based Approach & Traditional approaches \\
\hline Focus on form is unintentional & Focus on form is deliberate \\
\hline Communicative tasks are centred. & Communicative tasks are not mainly considered \\
\hline New language is confronted unintentional during tasks. & New language is intentionally taught. \\
\hline There is little or no focus on specific language forms & There is remarkable focus on specific language forms. \\
\hline Lessons are mainly learner-centred. & Lessons are mainly teacher-led. \\
\hline
\end{tabular}

\section{LITERATURE REVIEW}

Past studies have shown that English language proficiency has an influence on English as a foreign language (EFL) students' academic performance at the university level (e.g., Songy, 2007; Stoynoff, 1997). Unlike direct approach or traditional approach, the communicative approach is regarded as an indirect approach to L2 instruction (Celce-Murcia, Dornyei, \& Terrell, 1997) and is also considered as a learner-cantered approach (Nunan, 1988). Task based originated from communicative language teaching (CLT). Hymes' view about communicative competence created a more critical view at language and highlighted the students' needs to provide opportunities to use language in the classroom. But there were two criticisms against it. In CLT Instead of assigning a syllabus that involves grammar and lexis, the 'communicative syllabus' was specified for those notions and functions to identify the learners' semantic and pragmatic needs and to meet their needs as efficiently as possible.

Therefore, Instead of learning some grammatical structures such as 'simple present tense' or 'infinitive' the syllabuses began by some items like 'making requests' or 'talking about present'. Although the communicative syllabus stated to determine notions and functions, it in fact determined linguistic realisations of those notions and functions.

Furthermore, CLT was methodological. That is, there was a stress on language use in the classroom, which was considered as a type of practice for language use in the real world. But in fact, the communicative approach that was used in the classroom was a 'weak form' of the approach. Since, there was still an interest to see the study of language form before language use. Actually tasks were applied to help 'free' production at the end of a controlled form-based teaching cycle. The tendency to learn was still made by the specification of a new structure or pattern. Language use was seen as subordinate to the study of language form. In contrast to CLT, Task based approach, looks at language use accompanied by the tasks that are located in the centre for both syllabus planning and methodology.

Allwright (1984) was among the first people who argued about the effectiveness of tasks as an input to learning that asked for the need of language instruction and focused on the need for language use. But the best recorded application 
of a task-based approach is found in Prabhu's procedural syllabus (Prabhu 1987). Procedural syllabus programs were made on the Bangalore Madras project by Prabhu in 1979-1984, which was apparently the first endeavour in a real taskbased syllabus. It's worthwhile to mention here that "The Bangalore Project", as it is known in the literature, was the start point in task-based learning popularity. It was developed after some dissatisfactory trends toward structural teaching in English as a Foreign Language, then Prabhu found that it's time to change teaching methodology. Before Prabhu, English was taught by a method called S-O-S (Structural Oral Situational). Much attention was paid to apply the S-O-S methodology. It was considered as a desirable methodology for ten years. But in 1975, when S-O-S was a prominent methodology, some criticisms were raised. Critics claimed that students were neither able to use the language outside the class, nor to get enough grammatical accuracy or situational appropriateness in their language, by the S-O-S pedagogy. Prabhu conducted a project in schools in India where learners were given a series of problems and information gap activities that they were asked to solve them under teacher's supervision. Prabhu claimed that a focus on language form prevents language learning. He believed that Language development is achieved by the outcome of natural processes. Assessments on Prabhu's project showed that learners were more successful in this way than other counterparts who were taught in a more traditional ways.

Long and Crookes (1992) defined task based syllabuses in three categories: (1) procedural syllabuses, (2) process syllabuses and (3) task-based language teaching. Ellis (2002) added another category that is known as "humanistic teaching". Ellis defined humanistic teaching as "humanistic principles of education emphasized the achievement of students' full potential for growth by acknowledging the importance of the affective dimension in learning as well as the cognitive" (2002, p.31).Long \& Crookes defined process syllabus as "a social and problem-solving orientation, with explicit provision for the expression of individual learning styles and preferences" (Long \& Crookes, 1992, p.38). Another approach that was similar to Prabhu's was proposed by Breen (1987) and Candlin (1987) in their support to a process syllabus. Breen and Candlin agreed with Prabhu. They also based the syllabus design and classroom methodology on the use of language rather than as a language item. The process syllabus is different from the procedural syllabus in two ways:

- The teacher's role is not one sided as an organiser, but he can consult learners and help them understand their own learning plan.

- In Prabhu's procedural approach students were operating with the process syllabus, they focused on language forms explicitly.

Long and Crookes (1992) criticised the procedural and process syllabuses in three parts:

(1)The syllabuses do not offer any procedures for task selection based on a need's analysis.

(2) They do not offer any criteria for task sequencing. (3) They do not permit a systematic focus on form, although the process syllabus may focus on form in response to learner initiative. Long and Crookes claimed that classroom or pedagogical tasks must be systematically related to communicative tasks that the learners will perform outside the classroom. Communicative needs should be determined and expressed by meanings and outcomes. These meanings and outcomes must be in relation with pedagogical tasks. However, the problem of task sequencing is more difficult. Few formal researches are conducted into task based approach in classrooms. R. Ellis (2000) illustrated the effects of some of the factors in examining task use from a 'sociocultural perspective'. He focused on the way that participants 'coconstructed the activity' they were involved in. In one of the few task based classroom studies Skehan and Foster(1998) attended to the influence of learners' ability to plan a task before performing, and to the effective role of teacher's guidance upon that planning. They did a research in three classes to record different types of task under different conditions; at last, the results of interactions were compared. In their findings many interesting and unexpected results were observed, but generally those learners who had planning time could produce a better and longer discourse than those had no planning time, generally they indicated a stronger engagement with the task itself.

\section{DEFINITIONS OF "TASK"}

Task is defined in different ways. Long (1985) defines it as "a piece of work undertaken for oneself or for others, freely or for some reward. Thus, examples of tasks include painting a fence, dressing a child, filling out a form, buying a pair of shoes. In other words, by 'task' is meant the hundred and one things people do in everyday life, at work, at play, and in between" (p.89). Nunan (2004) made a distinction between target tasks, and pedagogical tasks. According to him, target tasks refer to language use in the world beyond the classroom. Pedagogical tasks on the other hand refer to language use that occurs in the classroom. The word 'task' has broader meaning. It sometimes refers to 'metacommunicative tasks', or other exercises by focusing on language form, where learners use language or make generalisations about it. As a result, these definitions are non-technical and non-linguistic. Furthermore, some of the examples that are provided may not include language use at all (e.g. Draw something without talking). Therefore, each task can be part of a larger sequence of tasks, for example, the task of class activities for a teacher may be a part of the task to give 'final score". Pedagogical task in Breen's view is defined as "any structured language learning endeavour which has a particular objective, appropriate content, a specified working procedure, and a range of outcomes for those who undertake the task. 'Task' is therefore assumed to refer to a range of work plans which have the overall purposes of facilitating language learning - from the simple and brief exercise type, to more complex and lengthy activities such as group problem-solving or simulations and decision-making. (Breen, 1987, p. 23) 
But even this definition is not accurate since according to it everything that the learner does in the classroom is considered as a task. Then Willis (1996) gave another definition about it as "...where the target language is used by the learner for a communicative purpose (goal) in order to achieve an outcome". Here the notion of meaning is subsumed in 'outcome'. Language in a communicative task is seen as bringing about an outcome through the exchange of meanings. (p. 173).

\section{TASK BASED FEATURES}

Major characteristics of task based approach are outlined as:

$\sqrt{ }$ Task as a reflection of real world activity

$\sqrt{ }$ Task as the syllabus unit

$\checkmark$ Task as a learner -centred base

$\sqrt{ }$ Task as an ideal for second language acquisition condition

$\checkmark$ Task as an instrument to specify the parts to be concentrated in the next activities

The first characteristic, Task as a reflection of real world activity, is similar for all models of this approach. According to Breen (1987) tasks are defined as social and problem solving interaction. The second feature, Task as the syllabus unit, is more difficult than the first one, since new syllabuses do not involve a single method to identify the subject of any course but usually include several ways to deal with different features of the course. The third feature, Task as a learner -centred base, is regarded as a general characteristic for this approach by Breen and Nunan.Nunan supported increased learner-centred base. His views were relevant to task based approach. The fourth point, Task as an ideal for second language acquisition condition, was the base of Long and Crookes's model to task based approach. They claimed that this model is based on a second language acquisition project, on a classroom-oriented research, and on the bases of syllabus and course design. The last feature, Task as an instrument to specify the parts to be concentrated in the next activities, directly indicates the role for tasks in a cycle. However, different ways to select the type of tasks have been offered. Long outlined four steps for developing a task-based syllabus:

1. Set a need analysis program to get target tasks.

2. Sort out the target tasks into separate task types.

3. Base on the tsk type, set pedagogical tasks.

4. Choose pedagogical tasks and put them in order to form a task syllabus.

\section{TASK-BASED APPROACH IN TEACHING}

One evident outcome of this approach is the exchange of information in spoken or written language. Therefore teachers can ask learners to exchange and perform instructions, or to solve a problem, or to tell the story for their partners. In all of these activities we are looking for one goal which is making students independent of the language to achieve that goal. One of the major features of task based approach is that learners who perform a task are free to use any kind of language to achieve their outcome, in other words language forms are not determined in advance. Learners never take note of language inputs to produce them. As soon as they decide to apply language for purposeful communications, they try to find appropriate input to make new meanings. In fact, they are not willing to reproduce a series of language forms in target norms. Their purpose is to create a meaning system by which they will be able to operate rapidly and efficiently in real time. As a result in order to achieve this goal they will apply and expand language forms that they have been recently faced with, but they will also adopt some sorts of strategies that lead them to ignore grammatical nuance points and to make forms which are not prohibited by the target norms. Therefore, the purpose of a communicative task is to motivate learners to create a meaning system. But different learners use different strategies and different language forms to fulfill the goal. The design of a task-based oriented course includes paying attention to the steps or components of a lesson that has a task in its principals. Different designs have offered. However all of them have three phases in common which are illustrated in table 3. These phases are represented in a task-based lesson chronologically.

TABLE 3:

A FRAMEWORK FOR DESIGNING TASK-BASED LESSONS

\begin{tabular}{|l|l|}
\hline Phase & Examples of options \\
\hline A. Pre-task & * Setting out the activity \\
& * Planning time \\
& $*$ Doing a similar task \\
\hline B. During task & $*$ Time pressure \\
& $*$ Number of participants \\
\hline C. Post-task & $*$ Learner report \\
& $*$ Consciousness-raising \\
& $*$ Repeat task \\
\hline
\end{tabular}

As can be seen from the table 3, the first phase is called 'pre-task' that concerns with different activities that both teachers and students undertake before they start the task, the activities like giving students time to plan for the performance of the task. In the second phase, that is called 'during task' phase, the focus is on the task itself and it 
provides different pedagogical options, like identifying students' needs to perform during a specific time .The last phase is called 'post-task' and it includes procedures to follow-up the given task. In task based teaching 'during task' is the only compulsory phase. So, items that are selected from the 'pre-task' or 'post-task' phases are optional.

\section{WILLIS’S TASK BASED FRAMEWORK}

The application of tasks in the classroom makes variety. Willis, J. (1996) outlined the 'task cycle' with more profound details that is more practical with a real natural classroom. He said three phases are concerned:

a) Pre-task phase: Various activities were suggested by Willis for teachers to undertake the 'presentation stage'.

b) The task cycle: He described task cycle as task, planning and report. Students are expected to produce natural language, enhance fluency and confidence. Willis and Skehan emphasised on grammatical accuracy during the time tasks are being performed because during task performance the learners consider meaning and neglect grammatical correctness.

c) Language focus: It insists on some specific language features. As focus on meaning should be prominent, now it's time for 'language focus activities'. By language activities we mean semantics, lexis, morphology, syntax and phonetics/phonology. Figure 1 shows Willis's task based framework graphically.

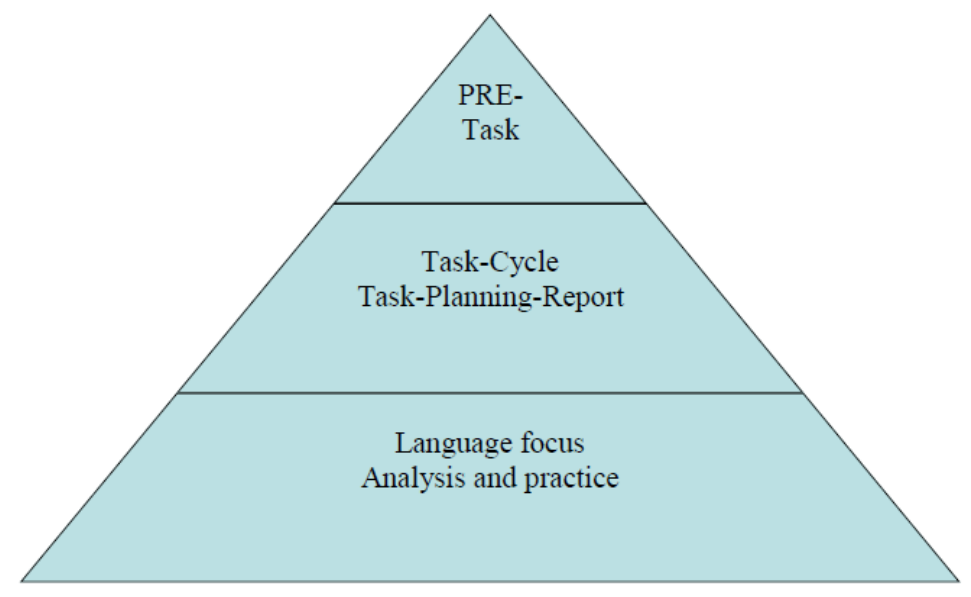

Fig. 1: Willis's framework in task based approach

\section{A. The Pre-task Phase}

The aim of the pre-task phase is to make students aware to carry out the task in ways that will enhance learning. This stage is regarded as an entry to the topic and task. It can consist of presenting useful words and phrases, brainstorming activities or listening to native speakers who are doing the tasks. Dornyei (2001) insisted on the importance of introducing a task in a way that encourages learners. He also emphasised on the value of explaining the purpose of the task. He also suggested that task preparation should include strategies that are in accordance with students' interests to perform the task.

Skehan (1998) pointed out that in pre task phase, a teacher has two options: To focus on the general meaning of the task or to focus on linguistic alternative. These two variables can be considered by one of these ways; (1) Advocate learners to perform tasks like their performance in during-task stage, (2) Ask learners to maintain a framework to perform the task, (3) Involve students in doing non-task activities to make them familiar how to perform the task (4) Make plan for the main task performance

\section{B. The Task Cycle}

This cycle includes three basic phases (Task, Planning, report) and one optional phase.

1. Task

Students start performing a communication task, by the background language they have already learned. The task is an aim-centred activity that enables the students to achieve a real outcome. According to Willis's category, we have six types of task:

1). Listing

2). Ordering and sorting

3). Comparing

4). Problem solving

5). Sharing personal experiences

6). Creative tasks 
Other activities like and practice activities are not considered as tasks. For each task a specific purpose is devoted that must be attained in a specific period of time. Students can select different language types to get into the goal of the task. Concentration of the task is on meaning rather than form. The teacher carefully controls the task and never corrects errors. For closed tasks there are specific goals and language forms are predictable to some extent, whereas for open tasks there are less specific goals and language forms are less predictable. For this stage, the teacher controls and encourages students to communicate in the target language. As mentioned before, the teacher does not correct errors but helps students to elaborate what they want to say. The emphasis is on automaticity and fluency.

\section{Planning}

After the task is finished, learners give a report on the outcome. Then attention is paid to organisation and accuracy. The teacher makes students aware of any errors they made in this stage and helps them for correction.

3. Report

All groups are asked to report a summary to the class. The other students listen in order to compare their findings or to do a research. At this stage, the teacher can paraphrase but not correct the language.

4. Optional post task listening

At this phase students can listen to native speakers who have done the same task and compare the language. Motivation is created by the need to attain the objectives of the task and to report back on it. If success is achieved, motivation will be increased. A kind of motivation can make by listening to native speakers who have done the task, because in accomplishing the task, students will find the gaps in their language, and will listen to a native speaker to hear how they express themselves. Learners attend to language features and reflect them, recycle the task, look through the text to find new items, and try to rehearse correct pronunciation.

\section{Language Focus}

This phase is achieved by two sections: Analysis and practice

1. Analysis

Students concentrate on forms and they ask some questions about language characteristics.

\section{Practice}

Based on the analysis results, teachers identify some activities. In this framework methodology provides conditions for language learning. The conditions are made by exposure to real language; there are some opportunities to use language in real conditions.

As far as form is concerned, Willis focused on post-task report, which could be a written task such as writing a report or a spoken one that students can focus on accuracy. This framework was very effective.

\section{COMPONENTS OF A TASK}

As can be seen in figure 2, tasks include some types of 'input' which can be verbal (dialogue) or nonverbal (pictures) accompanied by an activity that is originated by the input. This activity forms the learners' need. All tasks have both goals and roles for teachers and students. Therefore, a task can be defined as a piece of meaning- centred work that makes learners comprehend, produce and communicate in the target language. Figure 2 illustrates the components of task by Nunan graphically.
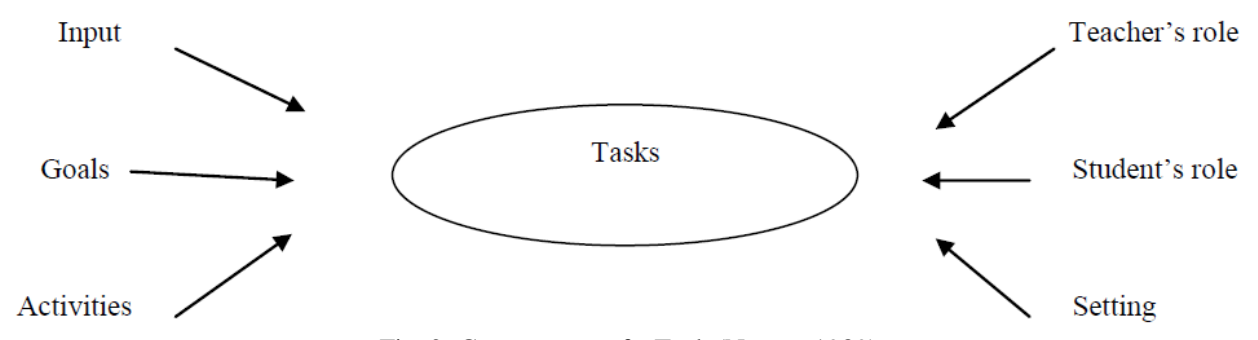

Fig. 2: Components of a Task (Nunan, 1989)

\section{CONCLUSION}

The more task base approach is studied the more necessity for sequencing of activities is observed. The controversial topic is to present a sequencing theme without any prevention in the learner's linguistic knowledge and his ability to get himself involved in the learning process. Therefore; teachers can apply a variety of communicative language teaching methodologies that consist of the best ways of teaching. In addition, the merged approach also includes a range of theories. 


\section{REFERENCES}

[1] Allwright, D. (1984). Why don't learners learn what teachers teach? The interaction hypothesis. In D. Singleton and D. Little (eds.). Language Learning in Formal and Informal Contexts (pp. 3- 18). Dublin: IRAL.

[2] Breen, M. (1987). Learner contributions to task design. In C. Candlin and D. Murphy (Eds.), Language Learning Tasks. Englewood Cliffs NJ: Prentice-Hall.

[3] Celce-Murcia, M., Dornyei, Z. \& Terrell, S. (1997). Direct approaches in L2 instruction: A turning point in communicative language teaching? TESOL Quarterly, 31(1), 141-152.

[4] Dornyei, Z. (2001). Motivational strategies in the classroom. Cambridge: Cambridge University Press.

[5] Ellis, R. (2000). Focussing on form: Towards a research agenda. In W. Renandya and N. Sunga (eds). Language Curriculum and Instruction in Multicultural Societies (pp. 123- 144). Singapore: SEAMEO Regional Language Centre.

[6] Ellis, R. (2002). Task-based language learning and teaching. Oxford: Oxford University Press.

[7] Long, Michael H. "A Role for Instruction in Second Language Acquisition: Task-Based Language Training." Modelling and Assessing Second Language Acquisition. Ed. Kenneth Hyltenstam and Manfred Pienemann. Clevedon: Multilingual Matters, 1985. 77-99.

[8] Long, M., \& Crookes, G. (1992). Three approaches to task-based syllabus design. Tesol Quarterly, 26(1), 27-55.

[9] Nunan, D. (1988). The learner-centred curriculum. Cambridge University Press: New York.

[10] Prabhu, N. (1987). Second Language Pedagogy. Oxford: Oxford University Press.

[11] Skehan, P. (1996a). A framework for the implementation of task-based instruction. Applied Linguistics 17, 38-62.

[12] Skehan, P. (1998). A cognitive approach to language learning. Oxford: Oxford University Press.

[13] Songy, D. G. (2007). Predicting success in academic achievement of major seminarians in Papua New Guinea: A comparison of cognitive test results and grade point averages. Contemporary PNG Studies, 7, 59-71.

[14] Stoynoff, S. (1977). Factors Associated with International Students' Academic Achievement. Journal of Instructional Psychology, 24(1), 56-68.

[15] Willis, D. (1996). A Framework for Task-Based Learning. London: Longman.

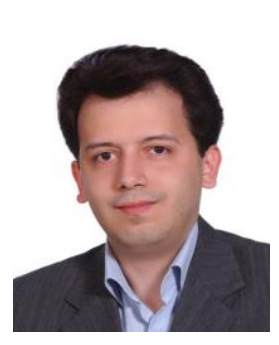

Sayed Mahdi Rozati was born in Iran-Esfahan in 1980. He received his BA in English translation and his MA in teaching. He has been teaching IELTS and TOEFL preparation courses to advance Iranian EFL candidates for 7 years. His research interests are Idiom, vocabulary, and task based development. 